\section{Vibration white finger: a newly prescribed disease}

Three new prescribed industrial diseases came into force in April 1985-vibration white finger, bilateral diffuse pleural thickening, and lung cancer when accompanied by asbestosis or bilateral diffuse pleural thickening.

Whether vibration white finger should be prescribed has been under consideration since March 1950 - so why the 35 year delay? During this interval the government has reported on vibration white finger, or Raynaud's phenomenon of occupational origin, in $1954,1970,1975$, and $1981 .^{2}$ The first report in 1954 decided against prescription-_a condition which will give rise to a large number of claims of which the great majority would have to be disallowed either because the disablement was so trivial or because of the difficulty of distinguishing between occupational and non-occupational cases." Twelve of the members of the Industrial Injuries Advisory Council advised against prescription and five associated themselves with a minority report in favour. One member (the late Dr L G Norman, of London Transport) advised that Raynaud's phenomenon caused by the use of handheld vibratory tools should be a prescribed disease with the limitation that a claimant should not qualify for disablement benefit unless his loss of faculty exceeded $10 \%$.

Throughout the 1960s and 1970s it became obvious that the lack of progress in settling this issue stemmed from our ignorance of the fundamental physiological processes in both primary Raynaud's disease (1864) ${ }^{3}$ and secondary Raynaud's phenomenon. ${ }^{4}$ The early clinicians concentrated on the periodic blanching of the fingers induced by exposure to cold (the main complaint from the people exposed to vibration). ${ }^{56}$ By the 1970s research indicated that degenerative changes were occurring in three other systems: neurological (including nerve endings), musculoskeletal, and possibly bone. Furthermore, if the vibration level was raised sufficiently (in impact percussive tools) and the exposure time prolonged (say, 10 to 20 years), then the digital arterial system would finally occlude producing tissue necrosis of the finger pulps. ${ }^{?}$

For medicolegal purposes the clinician has had to concentrate on an accurate differential diagnosis excluding primary Raynaud's disease, digital fractures and lacerations, large vessel obstruction (costoclavicular syndrome), collagen and rheumatoid disease, haematological dyscrasias, and the use of vasoconstrictor medication. Two other occupational disorders, the carpal tunnel syndrome arising from repetitive wrist movements ${ }^{8}$ and scleroderma, ${ }^{9}$ have also to be excluded.

Now that vibration white finger has been prescribed the greatest challenge to examining physicians will come from the assessment, classification, and estimation of impairment. Early cases have rightly been excluded from prescription. Apart from the sensitivity to cold producing partial blanching of digits with numbness such people have no evidence of reduced work performance, loss of employment, or interference with social or hobby activities. In advanced cases, however, loss of manual dexterity and manipulative skills together with attacks of vibration white finger often restrict activities at work and in the home and cause withdrawal from hobbies (golf, fishing, swimming, and so on). Nevertheless, the physician has to rely completely on the patient's own history of vibration white finger, and the absence of a reliable, sensitive, repeatable objective test for impairment has been the main reason for the government's indecision since 1954 . These difficulties are being slowly resolved by fundamental work on a scheme for international classification of impairment, ${ }^{10}$ on dose effect relations leading to international limits for vibration, ${ }^{11-13}$ and on the role of the mechanoreceptor afferent fibres innervating the glabrous skin in contact with the vibrating surfaces. ${ }^{14}$

Special investigations for vibration white finger include the Lewis-Prusik test for nail bed compression, Allen's test for digital blood flow, Adson's test for thoracic outlet compression, the Tinel and Phalen tests for carpal tunnel syndrome, the dynamometer test for grip strength, and two point and depth sense aesthesiometry for nerve impairment. The most promising single objective test is cold provocation in laboratory conditions with a recording of recovery of digital temperature. ${ }^{15-17}$ Vibrotactile finger pulp threshold measurements are being investigated at the University of Southampton, the National Research Council of Canada in Ottawa, and the University of Windsor, Ontario.

When the person is withdrawn from vibration does the hand-arm syndrome become reversed? Recent evidence suggests that advanced stages in patients aged 45 and over (stage 3 on the Taylor-Pelmear classification) are irreversible and may even deteriorate. ${ }^{1819}$ The probable reversibility point is an early stage 2 in a patient under 45 with the sensory component (numbness) more resistant to recovery than the arterial system. Gemne and his colleagues have attempted to assess another controversial diagnostic problem ${ }^{20}$-namely, the part played by the central autonomic nervous system in cases of established vibration white finger, in which it is said to produce psychosomatic symptoms-fatigue, headaches, sleep disturbance, irritability, vertigo, hyperhidrosis, and impotence. $^{21}$

The British government's inquiries into vibration white finger over the past 30 years have led to renewed research activity world wide. There have been three international meetings (Dundee, 1972; Cincinnati, 1975; Ottawa, 1981), and recently (May 1985) a fourth international symposium was held in the Finnish Institute of Occupational Health, Helsinki. Physicians examining for vibration white finger prescription will be concerned with a branch of medicine requiring specialised knowledge. Yet large gaps remain in our understanding of the pathophysiological mechanisms in the vibration syndrome ${ }^{22}$ - and relatively little progress has been made since Dr Maurice Raynaud wrote 123 years ago, ". . . one or more fingers becoming pale and cold. The determining cause is often the impression of cold. The cutaneous sensibility becomes blunted, then annihilated. It is the phenomenon known as the dead finger."

Emeritus Professor of Occupational Medicine,

William Taylor

University of Dundee

Dundee DD1 9SY

1 Social Security (Industrial Injuries, Prescribed Diseases) Amendment Regulations 1985. London HMSO, 1985. (SI No 1985/159.)

2 Department of Health and Social Security. Reports of Industrial Injuries Advisory Council (Social Security Act 1975) on vibration white finger. London: HMSO, 1954, 1970, 1975, 1981.

Raynaud M. On local asphyxia and symmetrical gangrene of the extremities. London: The New Sydenham Society, 1888. (Selected monographs.)

Loriga G. Il lavoro con i martelli pheumatici. Boll Inspett Lavaro 1911;2:35-60. (Cited by T E L Ekyl. Occupation and health supplement. Geneva: International Labour Office, 1938.)

Hamilton A. A study of spastic anemia in the hands of stone-cutters. Washington: Government Printing Office, 1918. (Bulletin of the US Bureau of Labor Statistics, No 236.)

6 Rothstein T. Report of the physical findings in eight stone-cutters from the limestone region of Indiana. Washington: Government Printing Office, 1918. (Bulletin of the US Bureau of Labor Statistics, No 236.)

7 Taylor W, Ogston S, Brammer AJ. A clinical assessment of seventy-eight cases of the hand-arm vibration syndrome. Proceedings of the 4 th international symposium on hand-arm vibration. Finland: Institute of Occupational Health, Helsinki (in press).

8 Lukas E. Peripheral nervous system and hand-arm vibration exposure. In: Brammer AJ, Taylor $\mathrm{W}$, eds. Vibration effects on the hand and arm in industry. New York: Wiley, 1981:39-43. 
9 Taylor W, Pelmear PL. Scleroderma and its relation to Raynaud's phenomenon of occupational origin. Ontario: Ministry of Labour, Occupational Health and Safety Division, Toronto, Canada, 1985. (Occupational Health in Ontario 1985;6: No 2.)

10 Pyykkö I. Health effects and evaluation of the hand-arm vibration. Proceedings of the 4th international symposium on hand-arm vibration. Finland: Institute of Occupational Health, Helsinki (in press).

11 International Organisation for Standardisation. Draft international standard: ISO/DIS/5349. Guidelines for the measurement and the assessment of human exposure to hand-transmitted vibration. Geneva: International Organisation for Standardisation, 1984.

12 British Standards Institution. Draft for development, DD 43-1975. Guide to the evaluation of exposure of the human hand-arm system to vibration. London: British Standards Institution, 1983. exposure of the human hand-arm system to vibration. London: British Standards Institution, 1983.
American Conference of Governmental Industrial Hygierists. Threshold limit values for chemical substances and physical agents in the work environment. Cincinnati, Ohio: ACGIH, 1984-5:111-6. substances and physical agents in the work environment. Cincinnati, Ohio: ACGIH, 1984-5:111-6.
Johansson RS, Landström U, Lundström R. Responses of mechanoreceptive afferent units in the 14 Johansson RS, Landström U, Lundström R. Responses of mechanoreceptive afferent units in the
glabrous skin of the human hand to sinusoidal skin displacements. Brain Res 1982;244:17-25. 5 Juul C, Nielsen SL. Locally induced digital vasospasm detected by delayed rewarming in Raynaud's phenomenon of occupational origin. Brf Ind Med 1981;38:87-90.

16 Welsh CL. Digital rewarming time in the assessment of vibration-induced white finger. Proceedings of the 4th international symposium on hand-arm vibration. Finland: Institute of Occupational Health, Helsinki (in press).

17 Welsh CL. The effect of vibration on digital blood flow. Br J Surg 1980;67:708-10.

18 Bursh JH. Vibration-induced white finger-reversible or not? A preliminary report. In: Brammer AJ, Taylor W, eds. Vibration effects on the hand and arm in industry. New York: Wiley, 1982: $193-7$

19 Futatsuka $M$, Ueno $T$, Sakurai $T$. Follow up study of vibration-induced white finger in chain saw operators. Br f Ind Med 1985;42:267-71.

20 Gemne G, Taylor $\mathrm{W}$, eds. Hand-arm vibration and the central autonomic nervous system. Special volume of the fournal of Low Frequency, Noise, and Vibration. London: Multi-Science, 1983.

21 Futatsuka M, Yasutake N, Sakurai T, Matsumoto T. Comparative study of vibration disease among operators of vibrating tools by factor analysis. Brf Ind Med 1985;42:260-6.

22 Olsen N, Fjeldborg P, Brøchner-Mortensen J. Sympathetic and local vasoconstrictor response to cold in vibration-induced white finger. BrF Ind Med 1985;42:272-5.

\section{Helping the sick doctor: a new service}

As a member of the Merrison Committee of Inquiry into the Regulation of the Medical Profession I was very struck by the evidence we received concerning sick doctors. There were many dismal stories about practitioners whose competence to practise had plainly been impaired by illness, often psychiatric, but who soldiered on to the distress of their families and to the alarm of their colleagues.

Recommendations that the General Medical Council should establish a health committee were accepted by the government and found expression in the Medical Act 1978. We hoped that by holding proceedings in camera and by adopting a constructive attitude sick, incompetent doctors would be controlled and brought to treatment at an early stage.

The health procedures of the General Medical Council have turned out, probably inevitably, to be more formal (though still private) than the Merrison report envisaged. Nevertheless, within these constraints the council has accomplished excellent work in reclaiming sick doctors.

In the NHS hospital service controls operate through professional panels (the old "three wise men" arrangements), and in general practice the local medical committees may recommend suspension to a family practitioner committee. Experience suggests, however, that these statutory NHS devices are poorly understood and patchy in their application.

Many factors operate to deter a sick doctor from receiving help. Those with alcoholism or in morbid depression may have a profound lack of insight. The sick doctor may feel awkward and embarrassed at the thought of approaching colleagues in his own locality. He might, however, be willing to accept aid from further afield, but may not be sure whom to contact or may lack the initiative. His local colleagues, while experiencing growing concern, may hesitate to take action which might be construed as meddlesome or disloyal and instead develop a kind of protective collusion with the doctor.
In many cases there may be a stage in the evolution of the disorder when the sick doctor might be receptive and amenable to an offer of professional help from outside his region. It could be argued that such a step cuts across and abrogates the role of the doctor's own general practitionerbut for reasons which have been touched on above he may be impotent.

In an attempt to fill this gap informal services have been set up in Britain - notably by the Association of Anaesthetists of Great Britain and also by the Association of Surgeons. More recently, after an initiative by the British Medical Association supported by the Royal Colleges and Faculties, the Joint Consultants' Committee, and other professional medical bodies, a National Counselling and Welfare Service for Sick Doctors has been opened for all branches of the profession. This is controlled by an autonomous national management committee, including representatives from the interested medical organisations. The scheme is non-coercive, informal, and confidential. Any doctor who is seriously concerned about the effects of illness on the fitness to practise of a colleague may telephone a central contact point (01580 3160). He will be asked merely for the specialty of the sick doctor and the area in which he or she works. The name and telephone number of a national adviser will be provided, who will be one of a panel of senior doctors (nominated by the colleges and the BMA) in the same branch of medicine as the "patient." The colleague may then telephone the national adviser, and only at this stage need disclose names. The adviser, having discussed the problem, may himself make an approach to the "patient" or may arrange for another specialist within the service to do so.

This stage of direct approach is clearly the crucial and most difficult part of the operation. Sensitive handling by the national adviser will be of the essence. Many sick and troubled doctors may, however, respond to this proffered lifeline with a huge sense of relief. Some may even wish to seek help from the service on their own initiative.

No permanent records incorporating names will be kept of these transactions. The "patient" is perfectly entitled to refuse the offer-in which case the original referring colleague is informed and the matter closed so far as the counselling service is concerned.

K RAWNSLEY

Chairman, Management Committee,

National Counselling and Welfare Service for Sick Doctors, 7 Marylebone Road,

London NW1

\section{National Counselling and Welfare Service for Sick Doctors}

A confidential independent service supported by the Royal Colleges, $\mathcal{F C C}, B M A$, and other professional bodies

Are you concerned about a colleague whose health is affecting his or her work and who seems reluctant to acknowledge this or to seek help? Advice is available from senior doctors in all branches of the profession on a strictly confidential and informal basis.

Telephone the national contact point (01 5803160 ) for the name of an appropriate adviser. 